\title{
14 Media modalities of theatrical space
}

\author{
Heidrun Führer and Janneke Schoene
}

When 'theatre' is mentioned, very different experiences can come to mind: one might recall seeing a specific play at a particular theatre, for example, attending a performance of Richard Wagner's opera The Flying Dutchmam (1843) at Malmö Opera in 2019 or watching the musical Beauty and the Beast in Disneyland's Royal Theatre (repeatedly staged there). One might consider theatre to be an embedded environmental situation: the architecture of the building in which the performance took place or a long evening with friends when one watched a staged performance. One might even think of theatre being public performances in galleries or happenings in the street, where one can suddenly encounter any kind of performance such as a flash mob or pantomime. This chapter focuses on 'theatre' in its plural forms and its intermedial modalities. It aims to link concepts stemming from ancient philosophy and post-dramatic theatre with modern intermedial theory.

\section{What is theatre? Intertwining buildings and events}

As just indicated, the notion of theatre might refer to the theatre or to a specific theatre play, such as Wagner's The Flying Dutchman or Shakespeare's comedy A Midsummer Night's Dream (1595/96). Both of these plays were written to be performed in specific theatre buildings - Wagner's in the Bayreuth Festival Theatre, built in 1876, and Shakespeare's in the Globe Theatre, probably constructed in 1599. Often, though, theatre plays are not considered to be bound to a specific materiality, technical medium or a specific building. Rather, theatrical performances are known to travel from place to place and from group to group throughout time. They are always transformed to fit specific historical situations, languages and audiences of a particular place and in a particular context. Still, these theatrical performances gain their identity also via their architectural information. Theatre is more than a cultural 'text' that can be identified by the authors' names, the title and the story. Even when theatre is classified according to the intermedial basic media of word, image, or music, often, no further attention is paid to the surrounding material and additional technical conditions that stipulate the 'atmospheric' condition of theatre as a form of human communication. In this chapter, we explore the

DOI: $10.4324 / 9781003174288-17$ 


\section{6}

Heidrun Führer and Janneke Schoene

media and modalities of theatre with a special focus on the material space and the technical medium of display.

Traditionally, theatre is divided into multiple literary submedia such as comedy, tragedy, image theatre, opera, musicals, etc. These genres distinguish different types of drama with respect to the dominating basic medium solution of the dramatic conflicts. However, when considering the material and technical conditions or modalities of theatre more in detail, some problematic oppositions become visible: that between live events, mediated in the presence of the theatrical stage, and a disseminated media product, displayed on TV or another technical medium occurs for example. The concept of theatre comprises multiple media products that can be considered both as 'live' and as reproducible media products.

Since the material and technical conditions of theatre continually change with the times, these variable conditions influence the semiotic modality of theatre as a technical medium of display. A famous Beatles performance from 1964 can exemplify this complex intertwinement. The performance was recorded as a live event for a TV show in a setting that imitated the Globe Theatre, a historical building that underlines the symbolism which can be attributed to the technical medium of display. In the case of the Beatles performance, the theatre supported not only the remediation of a famous scene from A Midsummer Night's Dream but also the parody of established theatre conventions by the Beatles. Thus, apart from the pre-written literary texts representing a fictitious storyworld, also the building sets the spatiotemporal, material and semiotic frame that includes the symbolism of this theatre building. An intermedial consideration of the performing stage also considers how a specific architectural space as the technical medium of display affects the interaction of performing bodies on stage, and how the performers and the auditorium create both shared and divergent time-spaces. Thus, in our intermedial perspective, theatre is a multimodal media type of multiple qualified media products and performative cultural events which are not only shaped by the basic and technical media but are also transformed by time, space, architectural conditions and the specific sociohistorical context.

To explore theatre as a multimodal transformative process of becoming, we need to give up such conventions as studying merely the content of written language as a cultural text on its own, separated from the specific material and spatiotemporal conditions of the actualized performance on stage. Instead of marginalizing these phenomena as surrounding 'context' or 'form', we emphasize the suffusion of the abstracted categories of 'text' and 'context', of 'form' and 'content' within any discourse. In other words, we integrate the space (form) of the architectural building and the actual event as material and spatiotemporal modalities of theatre instead of regarding them merely as 'institutional and technical submedia' (Wolff 2011, p. 2). This can be done by focusing on the complex intertwinement of the technical and basic media aspects with particular sociohistorical discourses and the non-linguistic performative space of a theatrical atmosphere. 
We can, for example, consider how the architectural material as a technical medium of display interplays with Disney's and Wagner's musical dramas and intensifies the communicative and affective impact on the audience. The spatial arrangement of the Royal Theatre in Disneyland harks back to an entertaining medieval theatre on the street or in a tent, where people and actors more informally meet and communicate, while Richard Wagner's theatre in Bayreuth is modelled after the idealized form of Ancient Greek theatre. How can the role of the theatre building be described in intermedial terms? Indeed, Wagner consciously changed some spatial arrangements to intensify the emotional impact on the audience. For instance, in his architectural arrangement of a proscenium theatre, the audience is separated from a single stage, as he transformed the ancient 'orchestra' into a purely instrumental performance place that disappears from the direct view of the spectators into a darkened space lower than the illuminated stage. This spatial organization enhances not only the sound and atmosphere of Wagner's music drama, but it also makes the single performance centre stage and helps the spectators to immerse in the theatrical event. However, when post-dramatic theatre gives up the unifying spatiotemporal arrangement of the proscenium theatre (see below), it explores the medial character of the body and the performative agency of the material and spatiotemporal modalitiy of the performance differently.

\section{The space and technology of Ancient Greek theatre}

It is always instructive to see how our modern understanding of theatre is related to specific cultural and historical discourses. Greek theatre has existed since at least the sixth century BC. The very term theatre highlights the importance of space and place for theatre to take place: the Greek 'theatron' means 'a place of seeing' or 'viewing place'. When sitting in a semi-circle-like architectural space in a concave shell-shaped area, the spectators could both see and hear the public performance of how human bodies presented spoken or sung dialogues and how they performed on two interrelated stages, the main stage for the actors and a second stage for the ancient chorus. On the second stage, called 'orchestra', which means the 'dancing space', the chorus had an intermediary function commenting for the watching audience on the performers' words and action on the first stage. The intermediary function of a chorus in a Greek drama is easier to grasp if a contemporary reader not only considers the dialogue and action of a contemporary play but also the complex spatial modalities of the theatre, that is the spatial arrangement and the material modality of the second stage. This creates the presence of three different spatiotemporal 'worlds': that of the spectators, that of the singing and dancing chorus, and that of the actors and the spatial design conveys their relation towards each other.

These material and spatiotemporal aspects also influence how the actors and the spectators perform and interact with each other. Additionally, the tradition of performing religious and ritualized processions complicates the spatiotemporal modality even further. When performing both inside and outside the theatre, the moving bodies alter the imaginative, affective, sonic and social 
qualities of the space and produce a complex semiotic modality of theatre. Accordingly, the material building is not to be understood as a housing with a fixed borderline opposing the real world (outside) and the fictive world (inside). Rather, it creates a dynamic line that produces different qualities and intensities of whatever is seen, heard and experienced as different modes of performance. In this regard, theatre is a heterogenous 'lived space', splittable into zones of different intensities. Similarly, also modern theatre architecture explores the design and experience of space broadly. The interaction of space with the material and the technological modalities also makes surprising sound effects possible (see post-dramatic theatre below).

In case you have the opportunity to visit an Ancient Greek open-air theatre and you try to speak from such a scene, you will be surprised how far you can hear the sound travelling up even to the highest places. The ancient masks decorating the actors' faces supported the transmission of soundwaves over spatial distances, whereas the basic features of standardized character types and repeated staged patterns helped the audience to recognize the acting both in the sensorial modality and understand their significance in semiotic modality.

The effect of theatrical events on the spatiotemporal co-present ancient spectators has often been technologically intensified. For instance, the stage(s) were modified to change the symbolic effects of the scenery to represent not one but multiple virtual time-spaces. This was and is done by applying more and more advanced visible or invisible stage technology. It influences the logic of the performed action as much as the theatrical codes and conventions stipulate the process of semiosis of the spectators. The best-known example of how ancient mechanical technology could influence the action on stage was for centuries a hand-powered flying system called 'deus ex machina'. It displayed and materialized the immaterial 'divine' power by staging unexpected appearances of 'a god coming from the machinery', as the Latin implies. As this technological stage device was most often used in comedies to bring the staged confusion to a neat end, there are doubts about how seriously the audience took the transcendent power that mystically intervened to solve the problems of the human beings.

\section{Box 14.1 Ancient Greek theory of theatre}

The understanding of Ancient Greek theatre, and theatre in general, has been much informed by the first theoretical treatise describing and analysing the praxis of different ancient performances, namely the Poetics by Aristotle (384-322 BCE). According to him, a dramatic, an epic and a lyrical mode can be distinguished. All three modes belong to the larger concept 'mimesis' ('to make and to bring something into being' and 'to imitate'), often merely called 'representation'. These different types of representation are recognized by their consistent and closed form and their well-structured matter or 'content'. While the lyrical and the epic form of enactment operate both with a narrative voice, the dramatic mode seems 'to bring something into being' by doing, by staging events, and by characters that directly communicate with 
their voices in a way that creates a plot or a story. This plot is also called 'diegesis'. On these grounds, comedy and tragedy are distinguished concerning the types of dramatic characters, the structural elements, such as their tragic or happy ending, as well as the rhetorical style of the language used. As these categories became normative genre distinctions, the theatre was reduced to a self-contained, intentional and meaningful media product. Thereby, the interactive performances of embodied humans in a specific spatiotemporal environment, the shifting media technology, and the spatial and social conditions of the theatre were disregarded. However, these elements influence actively the immaterial atmospheric elements of theatre and the experience of a performance.

\section{The qualifying modalities of a proscenium theatre}

In an intermedial perspective on theatre and performance, the influence of the material, sensorial and spatiotemporal qualities of theatre are considered. It analyses not only the written text but also the performative space, the stage technology and the architectural condition of theatre. All these conditions affect the potential interaction of actors and audiences and their sense of identity and community as an ephemeral event, unique in time and space. Thus, the question is not only whether the audience is absent or co-present, but also how the architectural conditions allow the spectators to interact other than mentally. More than being merely a material shelter, a theatre building becomes an influential technical medium of display. As such, it organizes multi-layered social and virtual time-spaces.

In general, the material modality and the architectural design of a theatre form the expectations and experience of the visitors and shape multiple layers of the (time-)spaces, sensorial and semiotic experiences. For example, one's first impression of the Malmö Opera, which was built during the first half of the twentieth century, might be that it is an innovative, modern theatre. Still, like a proscenium theatre, the architectural construction directs the audience into the heart of the building, namely the auditorium that faces the theatre stage. Nevertheless, the huge foyer provides more than a transitory space. It also has a representational function and provides communicative possibilities - before, inbetween and after the performance. This material and spatiotemproal potentiality is very much part of a theatre experience. For some visitors, the mingle in this social space might add another meaning to the play performed on stage.

The material design of the proscenium theatre appeared in the Western middle-class culture of the eighteenth century and transformed the ancient theatre into what is called the representational theatre. This understanding restricted theatre and performance to a (mostly verbal) representation or a text that was played in front of an undifferentiated and disembodied audience. Moreover, this material and spatial arrangement also separates the stage from the auditorium, where the bodies of the spectators disappear in the darkened 
space. Without moving they can merely gaze towards the central and illuminated stage where the storyworld unfolds, consisting of the bodies of the speaking or singing actors.

The proscenium theatre provides two physically separated spaces, the stage, and the auditorium, and arranges an invisible, so-called fourth wall that is symbolically marked by the curtains and the stage lighting. This spatial design favours the understanding of performance as 'mimesis', representation, or as a 'cultural text'. As this text is played in a metaphorical time-space on stage, it is regarded as 'fiction' according to the convention of the so-called 'suspension of disbelief. This contract invites the disembodied audience to immerse in the staged make-believe world with a coherent event construction and significant speeches (see Box 14.2.).

This intermedial concern of the material, spatiotemporal and semiotic aspects of theatre and the represented storyworld also reveals the specific historical conventions of the eighteenth century. At this time, the audience was taught to contemplate the aesthetic artwork by following specific social codes of behaviour in theatre. These codes differ not only from codes associated with other buildings and places that are not housing art, such as churches, marketplaces, shopping centres or football stadiums, but also from other forms of theatre, such as the Royal Theatre in Disneyland. Its tent-like structure and spatial arrangement hark back to a more informal medieval theatre tradition when all kinds of people gathered in the street or in a tent to be entertained by different kinds of spectacles for a while. This architectural material and spatial modality of the Royal Theatre can be unfolded in its semiotic modality: a tent implies not the same restricting social codes as a pompous theatre building grounded in ancient rituals and culture. One can understand that a Disney performance is made 'for all people' rather than for an elite gathered to see a serious opera in a proscenium theatre. As the spectators of a Disney theatre expect to be entertained rather than morally educated, they also interact both with the actors and the other spectators differnetly. They are not expected to contemplate and immerse in a distinct or fixed unity of performance.

In general, theatre grants or attributes agency to both humans and nonhuman things taking place in between the architectural construction, the stage technology, the staged performance and the interaction with the audience. The material arrangements do not only influence how the audience behaves and positions itself in space but also how the audience members experience and interact with the performance they are attending. Post-dramatic theatre breaks with these conventions in different ways.

\section{Box 14.2 The body as subject and object}

The spatiotemporal modality of architecture establishes many conventional expectations about what theatre means. Some of these conventions concern the role that human bodies play in theatre involving both performers and audience. The human body is a main and complex medium (see Chapter 12), 
and theatre performances often explore the tension between bodies felt as subjects and bodies experienced as objects.

When you consider yourself as a subject, you assume that you have a body of your own and that you can sense and experience the space, the atmosphere and the emotional energy of your surroundings. Feeling embodied like this means that your body seems to disappear in its task of coordinating the complex process of mediation (sensual and bodily perception, memory and imagination). However, when you consider your body as an object, you draw attention to its own materiality, its form and practice. As soon as you watch your body in the mirror, it becomes a sign and an object for you as for other spectators.

Traditionally, the bodies of the human actors are regarded as objects staging an autonomous fictitious world and the spectators as disembodied subjects who are silently immersed in the spatially and materially framed storyworld. However, no audience is a coherent mass of bodies outside history and social change. We know, for instance, that spectators of the ancient theatre talked, ate and continually came and went in search of even better entertainment, and that the visitors of Shakespeare's Globe Theatre were rowdy crowds and behaved according to sociohistorical codes so different from today.

The modern silent audience that obediently follows an accepted established theatre etiquette is a result of the material design of the proscenium theatre and an unspoken 'theatre contract' from the nineteenth century that defines a binary relation between two spatiotemporal worlds, that of the actors on stage, performing from the script, and that of the spectators, who learned to quietly contemplate the make-believe world of a 'representational' theatre. The post-dramatic theatre challenged in particular the idealized concept of the disembodied spectator.

\section{Post-dramatic theatre}

During the twentieth century, so-called post-dramatic theatre broke with multiple conventional practices, including the primacy of the dramatic text, the fourth wall, the 'suspension of disbelief, and the Aristotelian definitions of dramatic forms and norms. Post-dramatic theatre foregrounds the 'material situation of the performance on stage' (Lehmann 2006). It eventually even leaves the conventional architectural space and the figurative space of a theatrical stage to explore how people perform in their everyday physical and social spaces in real time. When city centres, public spaces, shopping malls, etc. are used as stages (e.g. by flash mobs), the distinction between performance art and the performance of everyday life is blurred. In this, post-dramatic theatre is in many regards linked to the development of performance art and the avantgarde practices of the Futurists and Dadaists.

A key aspect of post-dramatic theatre is to stress the ambivalence of the human body being both subject and object (see Box 14.2). It often incorporates 


\section{2}

Heidrun Führer and Janneke Schoene

not only the audience as co-subjects but also a metacommunicative reversal of roles in the plays. This shall be exemplified with some works of Christoph Schlingensief (1960-2010), German director and artist, who emphasized, among other things, the agency of material objects and spaces that have an impact on human bodies. Many of his plays and installations make those spaces interact that are traditionally kept apart. His constantly growing and changing installation Animatograph, for example, was a performative installation that travelled to different places. First shown in 2005 on the occasion of an art festival in Reykjavík, it was also set up in traditional theatre contexts such as the Burgtheater in Vienna and the Volksbühne in Berlin as well as in public places, such as a woodland in Germany or a small township nearby Lüderitz in Namibia.

The title of this installation refers to early types of animatographs or rather theatrographs from the nineteenth century. Back then, different images like photographs or paintings were projected both on actors on the stage but also on the audience. As a result, not only the staged play but also the audience became the object of the gaze and an integrated part of the 'real' play (Berka 2010). Thus, the installation consists of and generates different wooden segments and spaces with screens and projectors, each being used as a potential projection surface itself. When installed somewhere, overlapping images as well as sounds were constantly projected on and woven into the installation that came across as a living organism that includes bodies as basic media and potential technical media, again breaking conventional theatre structures. The audience could enter the maze-like and slowly moving 'stage' that became then an intermedial web of images, visual impressions, references and connotations. The use of modern technologies, parallel screenings and projections, and even revolving stages in Schlingensief's work, are neither bound to functionality nor the perfect illusion of a fictive make-believe world. Rather, they emphasize the mediality of the theatre performances. However, as theatre performances are often connected to fictionality, at least to some degree, the post-dramatic tendencies of Schlingensiefs theatre foreground the sociopolitical functions of performances rather than frames of illusion. In this regard, it rejects traditional differentiation between subject and object (see Box 14.2). In emphasizing the material and spatiotemporal modality, his theatre concept breaks down the fourth wall. Besides, by interconnecting all present bodies (both acting and non-acting) the complex process of mediation and the mediatization of self-referentiality becomes present.

As mentioned earlier, post-dramatic theatre particularly questions the conventional entanglement between bodily performances and theatre buildings, implying a distinction between reality and fiction. How this convention is disturbed, shall be exemplified with another work by Schlingensief. During his project Passion Impossible - 7 Day Emergency Call for Germany, Schlingensief left the classical theatre building of the Schauspielhaus Hamburg in 1997 and, dressed up as a police officer, interacted with other characters, the audience and people in the centre of the city. While Schlingensief's 'staging of the city' strived to emphasize the mediality of reality as a practice of representation itself, 
this appearance and acting was not clearly framed as art/theatre/performance. Therefore, also 'other' police officers did not stay in the conventionally passive role of spectators, but became active: they investigated Schlingensief's status as a police officer and thus explored the distinction between reality and play/illusion that is normally fundamental for separating qualified media products from the everyday life.

In short, any space can potentially become a stage. Thus, both material and non-material phenomena can create a multi-layered symbolic situation that can oscillate between the physical space and the fictional place. Even the performing bodies of actors and spectators oscillate between different roles: between being present in the 'here and now' and referring to an immaterial narrative of another 'reality' at the same time. Later, so-called flash mobs take up these post-dramatic tendencies although these ephemeral pop-up performances outside of the institutionalized, architectural spaces of theatres are less theoretically grounded in theatre studies. They also demonstrate that subjects can suddenly be turned into objects and the other way around. By drawing attention to themselves as unexpected interventions in public spaces (see Box 14.1), they, ideally, create 'zones' of a certain spatiotemporal intensity to supersede other institutionalized or even economic structures of partly organized, partly randomly co-present human bodies in public.

This development complicates the theoretical analysis drawing on fixed and generalized categories. A dynamic intermedial understanding of theatre emphasizes that performers and spectators 'act' together in performative spaces and times (Bowler 2015). In the words of theatre historian David Wiles, performative events should not be analysed separately from where they take place: 'the playas-text can be performed in a space, but the play-as-event belongs to the space, and makes the space perform as much as it makes the actors perform' (Wiles 2003 , p. 1). In addition, performances in and outside institutionalized theatrical buildings are shared perceptual and imaginative efforts of spatiotemporal and semiotic modalities that become entangled in the spectators' process of semiosis.

In summary, this chapter explored the shifting concept of theatre and theatrical performances from an intermedial perspective by foregrounding how the material and spatiotemporal modality becomes performative value. Theatre transforms the body into a technical medium of display. At the same time, the body is also a basic medium that oscillates between actor and spectator, active and passive, subject and object, fictitious and real. In particular, post-dramatic theatre draws from this tension. Therefore, theatre can be considered a collaborative media product whose dynamic borders challenge any fixed conceptualization.

\section{References}

Berka, R. 2010. Schlingensief's animatograph: Time here becomes space. In T. Forrest and A.T. Scheer, eds., Art without borders (pp. 169-186). Bristol: Intellect. 


\section{Heidrun Führer and Janneke Schoene}

Bowler, L.M. 2015. Theatre architecture as embodied space: A phenomenology of theatre buildings in performance, $\mathrm{PhD}$ thesis. München: Ludwig-Maximilians-University München. https:// edoc.ub.uni-muenchen.de/20310/7/Bowler_Lisa_Marie.pdf [Accessed 1 February 2021].

Lehmann, H.T. 2006. Postdramatic theatre. New York: Routledge.

Wiles, D. 2003. Short history of Western performance space. New York: Cambridge University Press.

Wolf, Werner. 2011. (Inter)mediality and the study of literature. CLCWeb: Comparative Literature and Culture, 13(3). 